\title{
Identifying the Risks Impacting on the Sustainable Development of a Tourism Area
}

\author{
Evgeniya Vidishcheva ${ }^{1,}{ }^{*}$, YuriyDreizis ${ }^{1}$, Andrey Kopyrin ${ }^{1}$ andMarina Gunare $^{2}$ \\ ${ }^{1}$ Sochi State University, 354000, Plastunskaya Str., 94-A, Sochi, Russia \\ ${ }^{2}$ Baltic International Academy,LV-1003,Lomonosova Str., 4, Riga, Latvia
}

\begin{abstract}
The sustainable development of most tourism areas is accompanied with ever-increasing recreational pressure and the evergrowing threat of depletion of their natural and recreational resources. All efforts at strategic planning or long-term forecasting may be baffled if there is insufficient understanding of where the risks are coming from and what impact they may have on the environment. It is of utmost significance for tourism areas to keep track of all risks attendant upon their path to sustainable development, which is about achieving balanced recreational pressure and a number of positive socio-economic effects. On balance, there is a need to identify the entire set of risks that may face an area as a result of tourism activity in it. This paper explores some of the key threats to the sustainable development of tourism areas, identifies some of the key risks inherent to the process, and proposes a method for rank-ordering the risks based on their gravity.
\end{abstract}

\section{Introduction}

The sustainable development of a tourism area implies the attainment by it of characteristics such as economic stability, a positive environmental situation, being in demand as a tourist destination, moderate anthropogenic pressure, and a socially satisfied community. The main reason urging tourism areas to shift to the principles of sustainable development is the focus on preserving their natural-resource originality. Resources such as the natural landscape, mineral springs, and other recreational resources form the basis of stable and sustainable development in the majority of resort regions.

To be able to work out and implement a sound program for the development of areas with narrow specialization - in particular, resort-and-recreation areas - it is highly important to anticipate and assess potential barriers and consequences arising through the process of achieving the targets. Managing sustainable development at a regional level involves keeping track of potential risks associated with the region's specialization. The integrated development of each region involves a wide spectrum of risks and risk-causing factors. Preliminary analysis of potential areas of risk helps minimize the likelihood of a particular threat arising and reduce the scale of potential negative effects from that - thanks to having explored potential scenarios ahead of time.

\footnotetext{
*Corresponding author: evgenia-vv@mail.ru
} 
Issues related to the assessment of risks to sustainable development of regions in general have previously been investigated by the following researchers: Pudikov (2006), Tishin (2015), Ivanova and Morozova (2015), and Bezdenezhnykh, Kadnichanskaya, and Kormanovskaya (2015). Risks to the sustainable development of tourism areas specifically have been explored by the following scholars: Istomin, Sokolov, Zorinova, and Slesareva (2013), Ural (2015), and Epler Wood, Milstein, and Ahamed-Broadhurst (2019). However, while the concept of sustainable development is quite popular today and is of particular relevance to tourism regions, there currently appears to be a paucity of research devoted to, specifically, the analysis of risks to the sustainable development of tourism areas specifically.

\section{Materials and Methods}

The purpose of this study was to identify the set of risks impacting on the development of a tourism area and precluding it from achieving a state of sustainable development and design a risk-ranking system that could be helpful in laying down the priorities that will inform decision-making moving forward.

The authors employed a set of empirical and theoretical methods, including data collection, exploration, and analysis, summarization, comparison, and classification.

\section{Results and discussion}

The current research base offers various classifications of the risks impacting tourism areas on their path to sustainable development. Based on the key components of sustainable development, the main areas where the risks tend to emerge are a region's economy, social sphere, and environment (Ural, 2015). Most of the related research by Russian and foreign scholars has been centered on the following two major approaches to classifying risk to a region's sustainable development: 1) classifying risk based on the afore-mentioned components of sustainable development; 2) classifying risk more broadly - geopolitical, technological, psychological, spatial, individual, and strategic risks [2, 7].

Development in a region is viewed as sustainable when there is a match between regional dynamics and certain criteria, which is expressed in balanced socio-economic growth and well-preserved natural-recreational resources in the area. Quantitatively, this balance is determined by the tourism area's throughput capacity, i.e. the maximum pressure that the area can withstand without damage done to its natural environment and its reputation as that of a place where people want to live and relax.

Given the special characteristics of the development of tourism as a whole and tourism region in particular in light of the latest socio-economic trends, researchers may find it reasonable to expand the roster of areas where the risks emerge and analyze the potential spheres of risk more thoroughly. The lack of a sound integrated system for assessing the risks impacting tourism areas is currently resulting in irrational distribution of resources in carrying out preventive risk-management activities.

It may be worth identifying a set of potential sources of risk to the development of a tourism area based on existing risk factors. Given that sustainable development is governed by the combined impact of various differently directed factors, possible sources of risk can be both destabilizing and positive phenomena in the internal and external environments. Figure 1 lists some of the key sources of risk to tourism areas, which include the following:

1) The environment. The environment is where the most dangerous of the risks are concentrated; these risks, which hardly lend themselves to forecasting and prevention, 
include threats caused by natural disasters, like floods, droughts, forest fires, infectious diseases, etc.

2) Economic activity. Economic activity produces a plethora of risks associated with the operation of local enterprises, the organization of the life-activity of tourists and the local community, and their impact on the environment. Among the potential threats from economic activity, the biggest challenge is posed by environmental risks. Air, land, and marine pollution is known to have a powerful accumulative effect, which can manifest itself decades later and can lead to highly negative consequences for the region's ecosystem, local community, and economy. The biggest danger to resort areas is the risk of depletion of their recreational potential, which is the main source and foundation of the regional economy's specialization.

3) The administrative apparatus. Errors in management and decision-making may give rise to the following risks: mismatch between the funding available and the objectives for development, irrational use of funds locally, unexpected spending, ineffective management, conflict situations, etc. [6, 7].

4) The social sphere. The social sphere produces the risk of conflicts and antagonisms arising between the region's locals, visitors, and authorities, which may lead to an outflow of manpower, a decline in the quality of the tourism product, and other negative effects.

5) Information. Regarded as a production factor in today's world, information is a powerful promotional tool, a critical tool for gaining competitive advantage, and a valuable tool for strategic planning and forecasting. The highest-priority risk in this segment is the use of unreliable or incomplete information in the decision-making process, in building the tourism area's image in the eyes of potential tourists, etc.

The authors' proposed set of sources of risk to the sustainable development of tourism areas is illustrated in Figure 1.

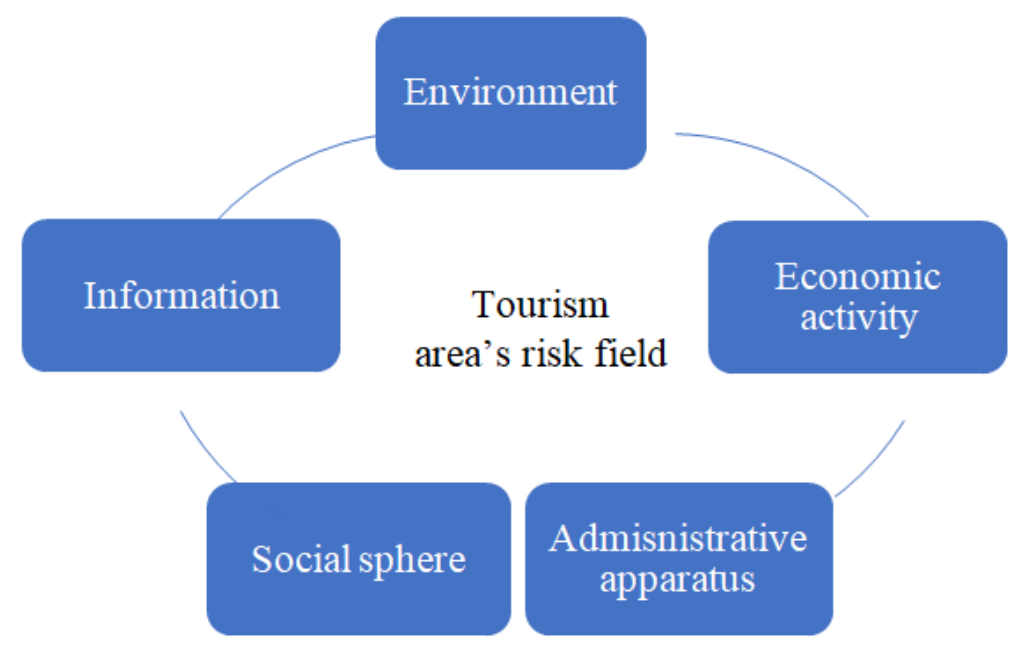

Fig. 1. Key sources of risk to the sustainable development of a tourism area. Produced by the authors

The current socio-economic situation in most tourism areas is characterized by an exacerbation of the mismatch between the outcomes of the accelerating processes of economic development and the potential for the harmonious coexistence of humanity and the environmental system.

Strategic planning is still largely performed today based on standard, conventional approaches, many of which do not take account of the characteristics of specific regions, which, doubtless, slows down the process of sustainable development and diminishes the 
efficiency of administration in the region. With this in mind and taking into account the diversity of the factors that expose a tourism region to risk, it is worth pointing up the following groups of risk to the sustainable development of tourism areas:

1) Natural-climatic and environmental risks. This includes events that can lead to environmentally unacceptable consequences for the area and its local community (e.g., a subpar waste treatment system, insufficient implementation of "green" technology, and opportunism on the part of the local community).

2) Economic and organizational-administrative risks. This group includes a system of general and specific threats that may affect the strategic management of the development of a region (e.g., insufficient funding available to support strategic development, excessive red tape, failure to tap innovation potential, and inert thinking in administration and business management).

3) Market-determined risks. This group includes potential threats caused by the purposeful activity of various entities operating in the market (e.g., being uncertain about the need for development and lacking motivation to strive for sustainability).

4) Social and staffing risks. This group includes threats to the social satisfaction, effective employment, and standard of living and quality of life of the local community (e.g., worsening social problems, a worsening demographic situation, and low labor productivity).

The level and composition of combined risk to sustainable development are governed by a set of particular factors of the internal and external environment, with the development of tourism-and-recreation areas tending to be influenced by the following factors:

- intensity of consumption of the region's recreational resources;

- anthropogenic and recreational pressure on the region's environment;

- degree to which the region's administration system is adapted to mixed areas (urbanized and natural areas);

- degree to which the region's production and socio-economic growth is moderate;

- degree to which the region's "green" economy potential is tapped;

- degree to which the process of urbanization of the region is adequate and manageable.

The sustainable development of a tourism region is highly dependent on the environmental situation, the amount of focus on the development of eco-friendly technology, and the infrastructural condition of business entities within it. A region's shift to development that is based on the principles of sustainability is normally accompanied by an optimization of the system of regional administration and control, which, in turn, may give rise to risk situations of an organizational-administrative and market-determined nature. The dynamic nature of sustainable development implies the occurrence of changes as a result of new approaches and methods being employed, as well as new economic processes emerging in the region, which makes it worth dividing existing risks into fundamental and acquired. The source of risk in this case is both positive and negative changes at various levels. Thus, the set of risks to a particular area is not permanent, and can change with the passage of time. This makes it worth dividing the risks into fundamental (socio-demographic, natural-environmental, and technogenic-industrial) and acquired (economic, political, and organizational-administrative) [6].

The basis of existing risk classifications is formed by attributes such as source of a risk, location of a risk's source, nature of a risk's origination, degree of its impact, likelihood of its manifestation, its duration, object of its impact, etc. Juxtaposing different classifications of risk may help arrive at the most complete set of risks to sustainable development in resort-and-recreation regions. Table 1 lists the risks that make up the basis of tourism areas' risk field in terms of sustainability in their development.

The above set is comprised of first-order threats, i.e. the largest-scale threats posing the most serious danger to tourism areas. Any management process involves the tracking of all 
possible groups of risk, including narrow- and low-likelihood risks, which are often derived from or are the consequence of first-order risks.

Table 1.The Authors' Set of the Most Serious Risks to the Sustainable Development of Tourism Areas (the First-Order Risks)

\begin{tabular}{|c|c|c|}
\hline Risks & Permanent & Temporary \\
\hline Internal & $\begin{array}{l}\text { Depletion of the region's } \\
\text { recreational resources } \\
\text { Non-compliance with } \\
\text { environmental standards } \\
\text { for activity } \\
\text { Administrative errors }\end{array}$ & $\begin{array}{c}\text { Destabilization of the investment climate and the } \\
\text { economic system in the region } \\
\text { Mismatch between political objectives and current trends } \\
\text { in the market } \\
\text { Interests of the local community being in conflict with } \\
\text { those of tourists } \\
\text { Declining standard of living in the region } \\
\text { Decline in share of highly-qualified personnel }\end{array}$ \\
\hline External & $\begin{array}{c}\text { Risks associated with } \\
\text { inevitable climatic } \\
\text { processes } \\
\text { Emergencies (e.g., } \\
\text { pandemics, floods, etc.) }\end{array}$ & $\begin{array}{l}\text { Global economic phenomena and processes } \\
\text { Geopolitical risks }\end{array}$ \\
\hline
\end{tabular}

When examining the risks to the sustainable development of regions, it is worth paying special attention to the interdependence and interconditionality of some of those risks. Recognizing the seriousness of a particular factor or source of risk suggests the need to not only develop a sound mechanism for eradicating it but assess any concomitant threats as well. In this context, there is a need to develop an efficient mechanism that will enable assessing and rank-ordering the potential risks. The gravity of a particular risk is determined based on the likelihood of it manifesting itself in a certain region and the size of potential damage from that. For instance, the risk of a technogenic disaster is a first-order risk to areas that have industrial specialization (e.g., nuclear power engineering, hydrocarbon production, etc.). With tourism areas, this risk is among those that are the least likely to occur, as they have no source for this risk in them. The risks listed in Table 1 are considered first-order risks, as they are able to not only cause negative phenomena in terms of the socio-economic situation in the area but also give rise to second- and higher-order risks.

Risk assessment and management are central to goal-setting and strategic planning. Having in place a system that will enable identifying and eradicating or mitigating various risk factors in a timely manner is essential to meeting strategic objectives for sustainable development in a region. Figure 2 illustrates the authors' proposed method for rankordering the risks based on their occurrence likelihood, impact, and consequences. 


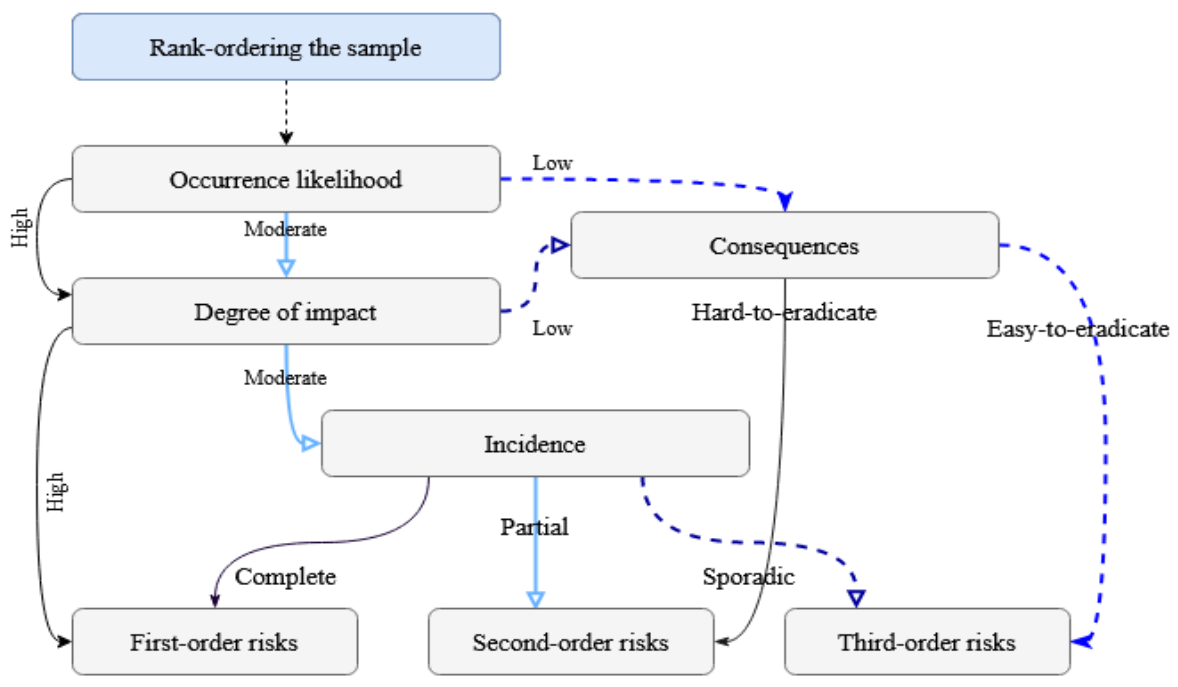

Fig. 2. Diagram illustrating the authors' proposed system for rank-ordering the risks to the sustainable development of tourism areas.

The algorithm involves stage-by-stage analysis of the risk parameters, starting with the assessment of the risk's occurrence likelihood and ending with the determination of its incidence. A first-order risk is a risk that is capable of giving rise, with the highest degree of probability, to negative processes in the tourism area's socio-economic environment. Preventing or eradicating this type of risk is a priority relative to all other risks. Among the key distinctive features of the management of risks within this group are continual control of and being prompt and proactive in reacting to them.

Second-order risks are characterized by less pronounced parameters, and in terms of their impact on the area can be viewed as local, as they affect not the entire area but only certain sectors of the system. Attributes that are common to risks within this group are low occurrence likelihood and low degree of impact. This group also includes low-probability but hard-to-eradicate risks. In addition, the overwhelming majority of risks within this category arise exclusively as a result of the manifestation of first-order risks.

The group of third-order risks comprises the least likely and dangerous threats, eradicating which does not normally require much effort and is not economically sensible to undertake. Rank-ordering the risks in this way can help optimize the risk-management system based on tackling risks of a particular order, which should help reduce the likelihood of various derived threats arising.

While second-order risks are less likely and dangerous, many are often derived from first-order threats. These include the following: increased emissions to the environment (a consequence of non-compliance with environmental standards for activity), declining natural diversity (depletion of recreational resources), being uncertain about the objectives for sustainable development at the administrative level (administrative risks), declining purchasing power of consumers (a destabilized economic system), etc. Many of the thirdand higher-order risks are a consequence of the manifestation of first- and second-order risks, which suggests the need to track and process them in a comprehensive manner too. The existence of this kind of relationship between the various forms and manifestations of risk helps optimize the risk management system via the elimination of redundant activities.

The general risk management methodology developed by Vidishcheva, Dreizis, and Kopyrin (2019) makes it possible to process even risks that do not easily yield themselves to control, which can be done through mitigating the effects of their occurrence and 
reducing the frequency of their manifestation. As per the model, the key stages in the process of management of risks to the sustainable development of tourism areas are as follows:

1. Identification of a risk's dangerous impacts (analysis of the risk field and concomitant factors; establishment of a relevant risk sample).

2. Assessment of the consequences of a risk occurring.

3. Integrated assessment of a risk.

4. Assessment of the degree to which a risk lends itself to control (i.e., can be contained or eradicated).

5. Development of scenarios for working with a risk.

What is in your resulting set of risks and, consequently, the potential extent and intensity of combined risk will depend on a whole set of permanent and variable environmental factors and may vary even for areas of similar specialization and development level. That being said, the magnitude of combined risk does not predetermine the likelihood of an area attaining a state of sustainable development.

\section{Conclusions}

An essential condition for the sustainable development of a tourism-and-recreation area is maintaining a balance among the economic, environmental, and social aspects of development. Carrying out consolidated assessments of an area's development with a focus on the fundamental components of sustainable development is an important stage in the process of strategic planning and forecasting it. Assessing the potential threats of a risk event occurring and the potential consequences of such an event at the stage of putting together the programming document will help determine the advisability of carrying out special-purpose activities to deal with the risk, and will help ensure quick and flexible decision-making in case there is a recognized need to adjust the program.

The study helped establish that the sustainable development of tourism areas is influenced by an integrated system of risks and risk-causing factors. Based on the distinctive characteristics of the type of areas under examination, the authors identified some of the key sources of risk for them, including the environment, information, the social sphere, economic activity, and the administrative apparatus. With that said, it is worth noting that there is currently a lack of a sound research base for the information and administrative aspects of risk eventuation. This substantiates the need to investigate the afore-mentioned sources of risk further in order to help enable complete control over risk during the strategic planning process at a regional level.

The risks to the sustainable development of tourism-and-recreation areas identified by this study may be nominally subsumed under the following five groups: (1) natural-climatic and environmental, (2) economic and organizational-administrative, (3) market-determined, (4) social, and (5) staffing. The proposed risk-ranking system can help identify the most dangerous and hard-to-eradicate risks, lay down one's priorities, and avoid duplicate riskmanagement activities.

In accordance with the study's objectives, the authors grouped the risks and determined a set of the most serious risks to the sustainable development of tourism areas. Identifying the set of risks impacting on the sustainable development of a tourism area can help determine the criteria and indicators on each of those risks that need to be assessed particularly thoroughly, as well as work out a relevant program of preventive and mitigating activities. 


\section{Acknowledgements}

The reported study was funded by RFBR and Krasnodar region according to the research project № 19-410-230049 p_a

\section{References}

1. N.R. Amirudin, A. Nawawi, A.S.A.P. Salin, Management \& Accounting Review, 16(1), 55 (2017)

2. T.I. Bezdenezhnykh, M.O. Kadnichanskaya, I.R. Kormanovskaya, Innovatsii, 7, 99 (2015)

3. M. Epler Wood, M. Milstein, and K. Ahamed-Broadhurst. Destinations at risk: The invisible burden of tourism (2019).

4. E.P. Istomin, A.G. Sokolov, E.M. Zorinova, L.S. Slesareva. Izvestiya YuFU, Tekhnicheskie Nauki, 9, 233 (2013)

5. S.S. Ivanova, Ya.S. Morozova. Fotinskie Chteniya, 1, 254 (2015)

6. P.N. Pudikov, Managing the risks to regional development (2006)

7. V.G. Tishin, The sustainable development of regions: The role and place of risk management in this process (2015)

8. M. Ural, Eur. J. of Tour., Hosp. and Recr, 7(1) (2015)

9. E.V. Vidishcheva, Yu.I. Dreizis, A.S. Kopyrin. Innovative Technologies in Environmental Science and Education (ITESE-2019), E3S Web of Conferences, 135, 03042 (2019) 